Supporting Information

\title{
Electrically Conductive Shell-Protective Layer Capping on Silicon Surface as Anode Material for High Performance Lithium-Ion Batteries
}

Ruiqi Na, ${ }^{\dagger}, \diamond$ Krysten Minnici, ${ }^{\dagger}$ Guoyan Zhang, ${ }^{\dagger}$ Nan Lu, ${ }^{\diamond}$ Miguel A. González, ${ }^{\dagger}$ Guibin Wang*, $\uparrow, \diamond$ and Elsa Reichmanis ${ }^{*}, \dagger, \uparrow, \uparrow, \dagger \dagger$

$\dagger$ Department of Chemical and Biomolecular Engineering, ††Department of Chemistry and Biochemistry, and $\uparrow \dagger \uparrow$ Department of Materials Science and Engineering, Georgia Institute of Technology, Atlanta, GA 30332, USA

$\diamond$ Key Laboratory of High Performance Plastics, Ministry of Education, College of Chemistry, Jilin University, Changchun, 130012, PR China

Correspondence and requests for materials should be addressed to *Guibin Wang (Email: $\quad \underline{w g b @ j l u . e d u . c n) ~ a n d ~ * E l s a ~ R e i c h m a n i s ~(E m a i l: ~}$ ereichmanis@,chbe.gatech.edu) 


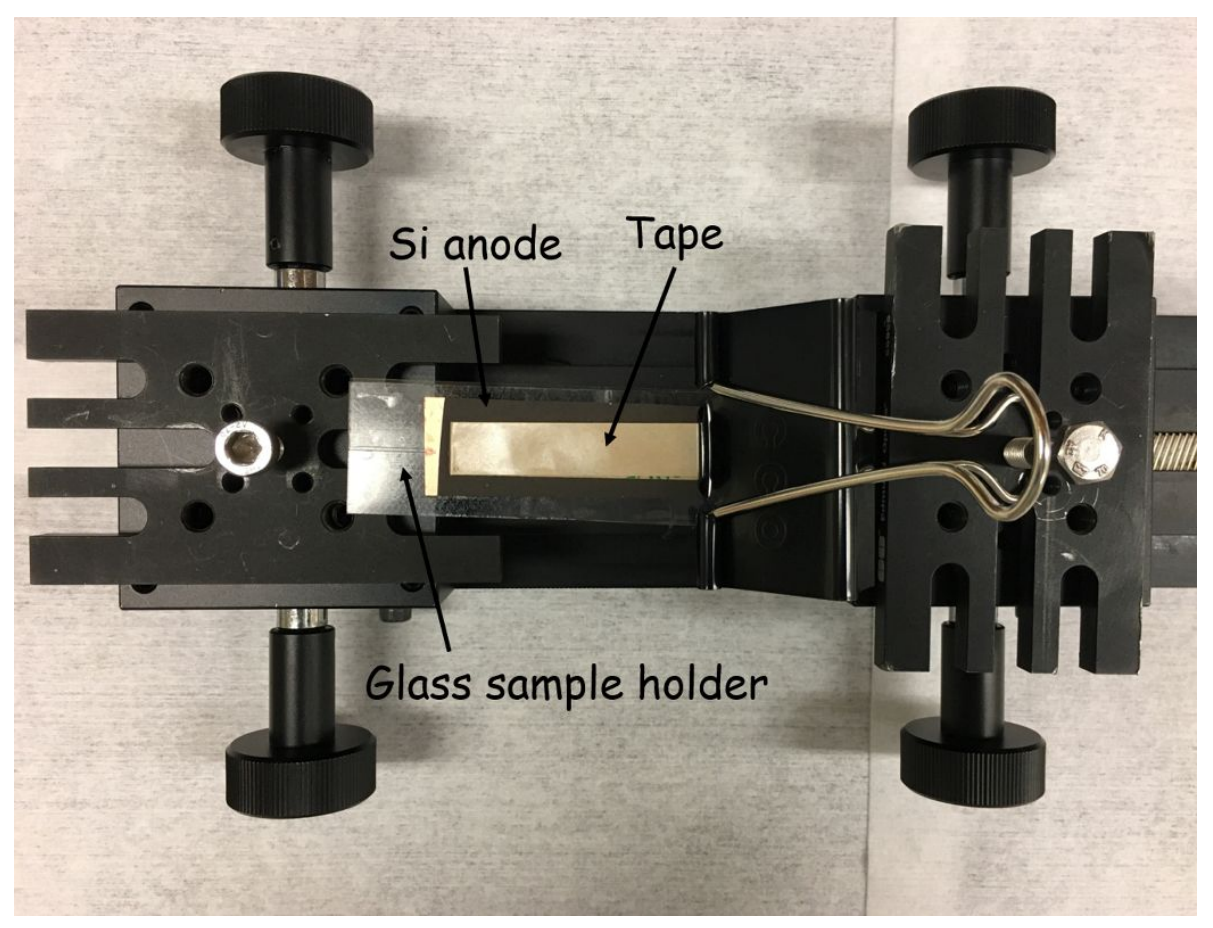

Figure S1. The optical photograph of the home-made peeling machine.

The $\mathrm{Cu}$ side of $\mathrm{Si}$ anode was firstly fixed to the left glass sample holder, then the Scotch Magic ${ }^{\circledR}$ tape was fixed to the right sample holder and the adhesive side of tape was firmly applied onto the electrode laminate side. After that the tape was peeled off by moving the right sample holder with a mechanical instrument at a rate of $5 \mathrm{~cm} \mathrm{~min}^{-1}$. 
(a)

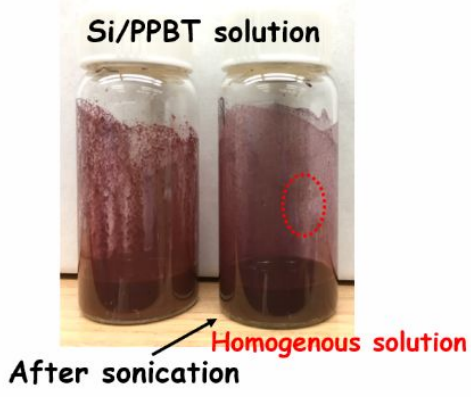

(c)

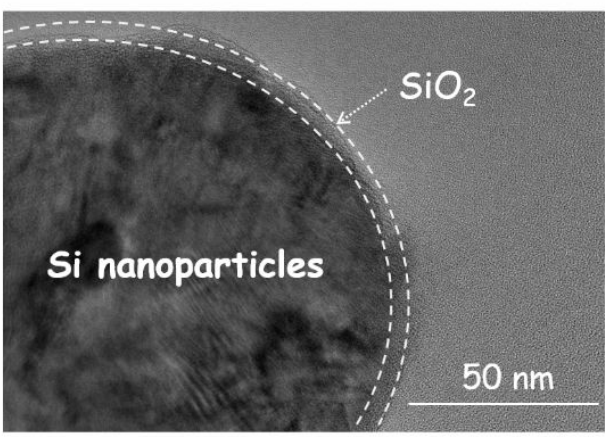

(b)

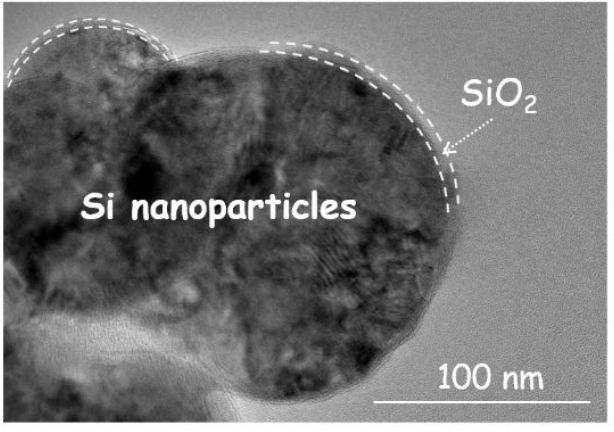

(d)

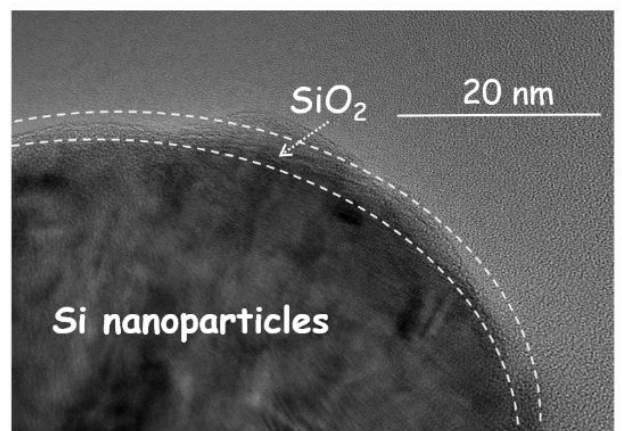

Figure S2. (a) Si/PPBT dispersion solution before and after probe-type sonication. After sonication process, the homogenous solution can be obtained. The TEM image of Si nanoparticles under different magnification: (b) $100 \mathrm{~nm}$, (c) $50 \mathrm{~nm}$ and (d) $20 \mathrm{~nm}$. The Si surface appears surrounded by an amorphous $\mathrm{SiO}_{2}$ layer. 


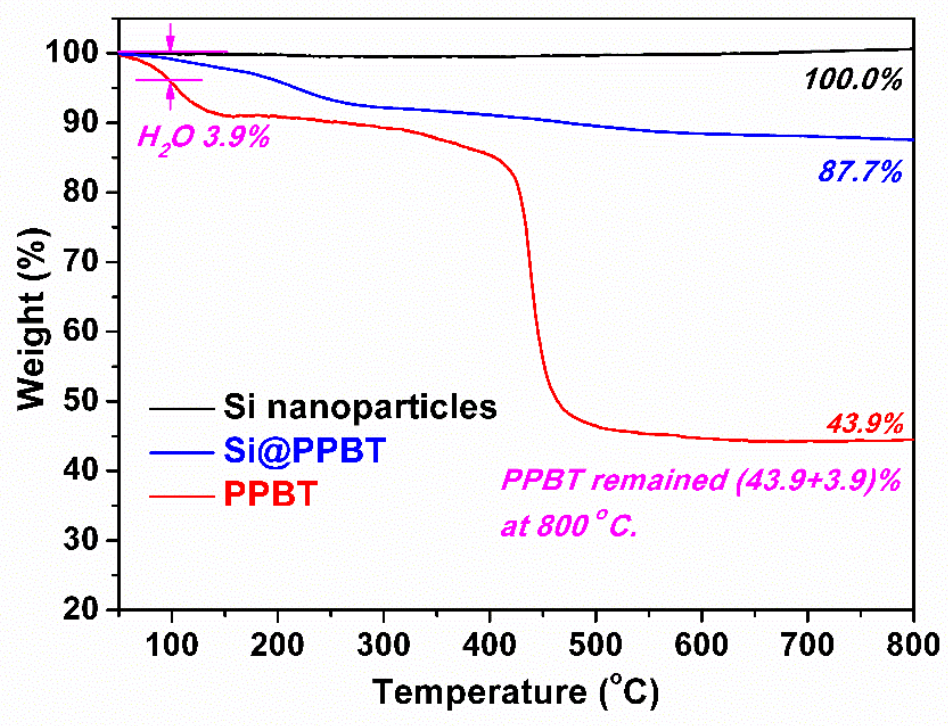

Figure S3. TGA curves of Si nanoparticles, PPBT polymer and Si@PPBT, which were carried out in $\mathrm{N}_{2}$ atmosphere at a heating rate of $10{ }^{\circ} \mathrm{C} \mathrm{min}^{-1}$ in the temperature range of $50-800{ }^{\circ} \mathrm{C}$.

\section{Before TGA test:}

Si@PPBT sample: 10 mg $\left(\mathrm{M}_{\mathrm{Si}}+\mathrm{M}_{\mathrm{PPBT}}=10 \mathrm{mg}\right)$.

\section{After TGA test:}

Remained Si@PPBT sample: $10 \times 87.7 \%=8.77 \mathrm{mg}\left(100.0 \% \mathrm{M}_{\mathrm{Si}}+47.8 \% \mathrm{M}_{\mathrm{PPBT}}=8.77\right)$.

$$
\begin{gathered}
\left\{\begin{array}{c}
\mathrm{M}_{\mathrm{Si}}+\mathrm{M}_{\mathrm{PPBT}}=10 \\
100.0 \% \mathrm{M}_{\mathrm{Si}}+47.8 \% \mathrm{M}_{\text {PPBT }}=8.77
\end{array}\right. \\
\mathrm{M}_{\mathrm{Si}}=\sim 7.64 \mathrm{mg} \quad \mathrm{M}_{\mathrm{PPBT}}=\sim 2.36 \mathrm{mg}
\end{gathered}
$$

After calculation, the amount of PPBT coated as the capping layer on the Si surface was around $\sim 23.6 \%$. 

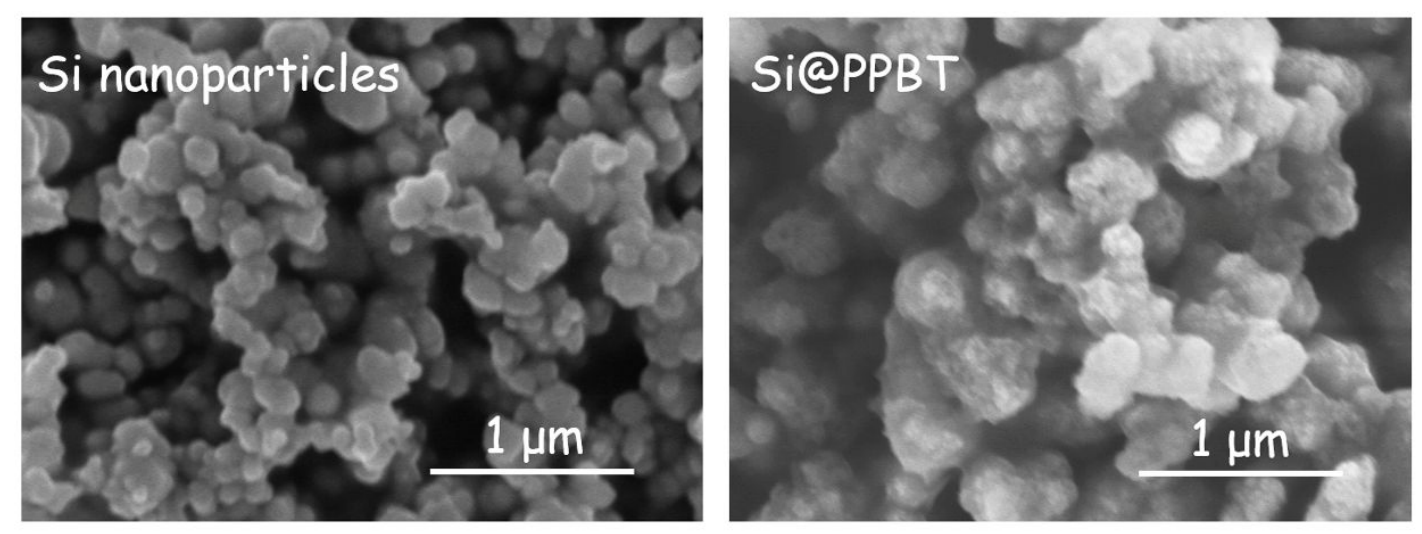

Figure S4. SEM images of Si nanoparticles (left) and Si@PPBT (right). 


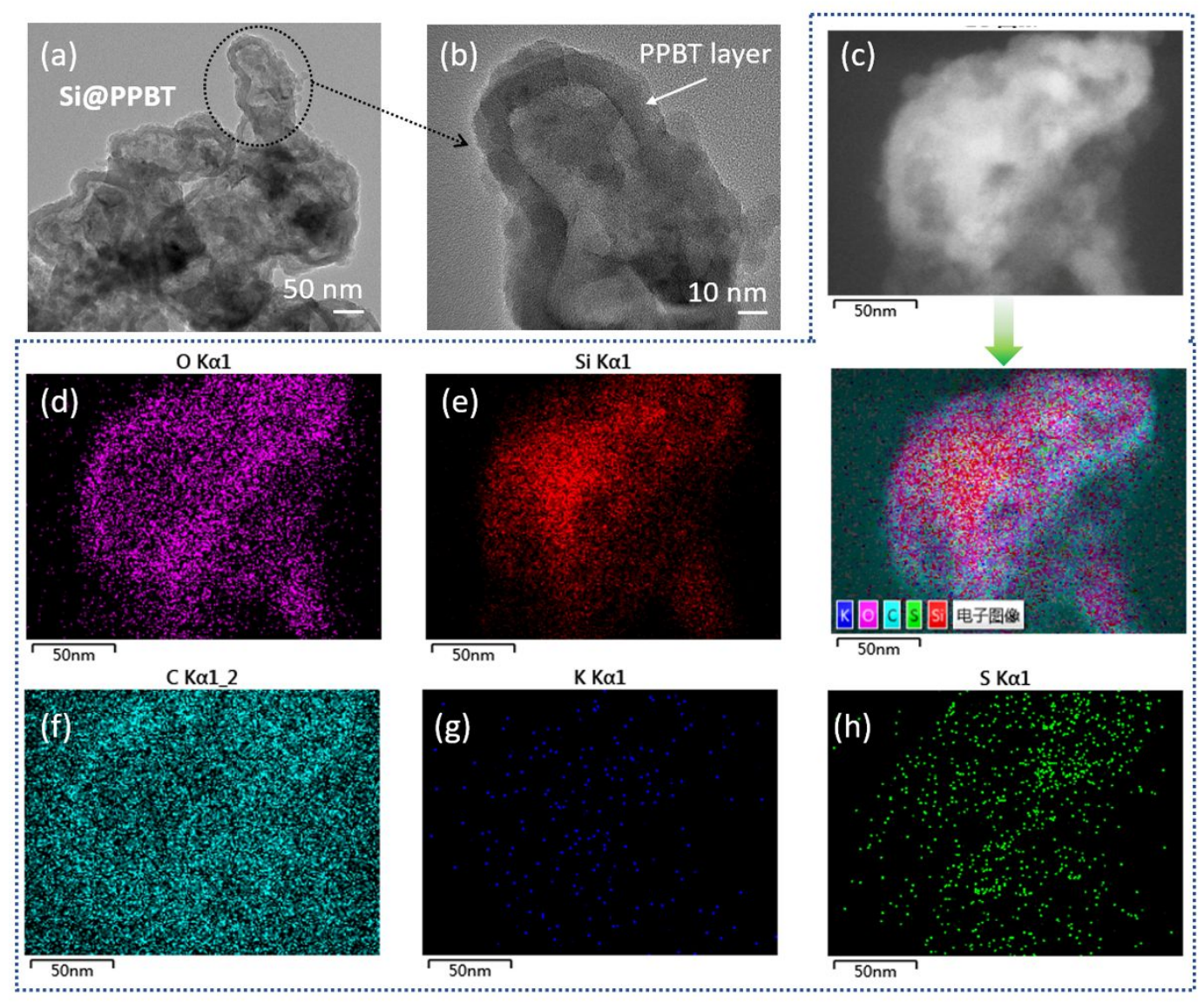

Figure S5. TEM images of Si@PPBT with different magnification; scale bar of (a) 50 nm, (b) 10 nm. (c-h) TEM and corresponding elemental mapping images of Si@PPBT.

TEM images (Figure S5a and b) revealed that Si@PPBT had a core-shell structure. Energy-dispersive X-ray spectroscopy (EDX) mapping of carbon (C), oxygen (O), potassium (K) and sulfur (S) confirmed formation of a homogeneous PPBT capping layer on the Si nanoparticle surface. 

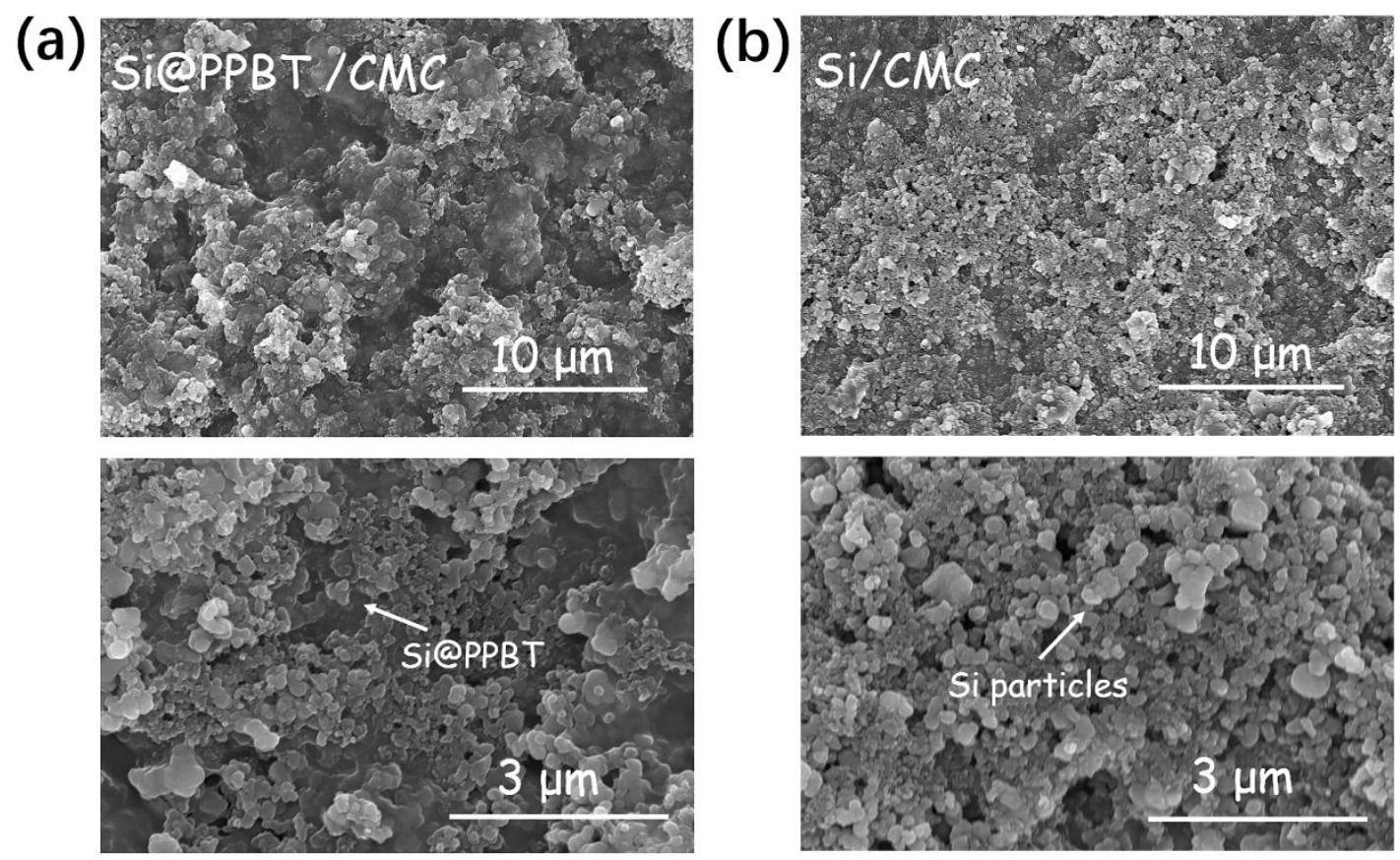

Figure S6. Surface SEM images of (a) Si@PPBT/CMC and (b) Si/CMC anodes. 


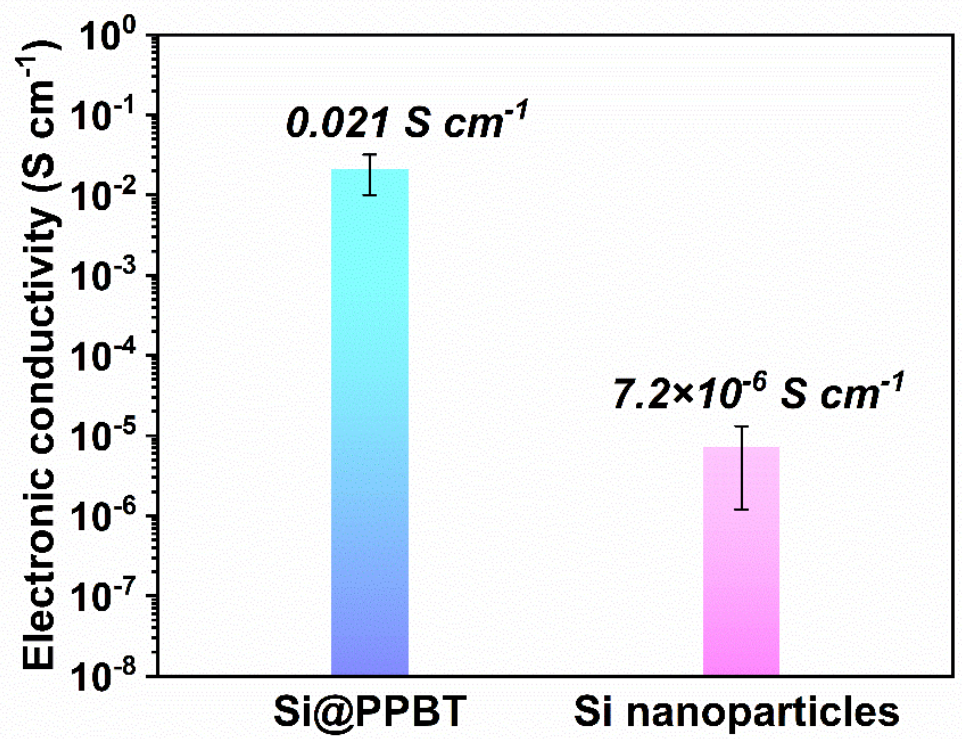

Figure S7. The intrinsic electronic conductivities of the Si@PPBT and Si nanoparticles. 


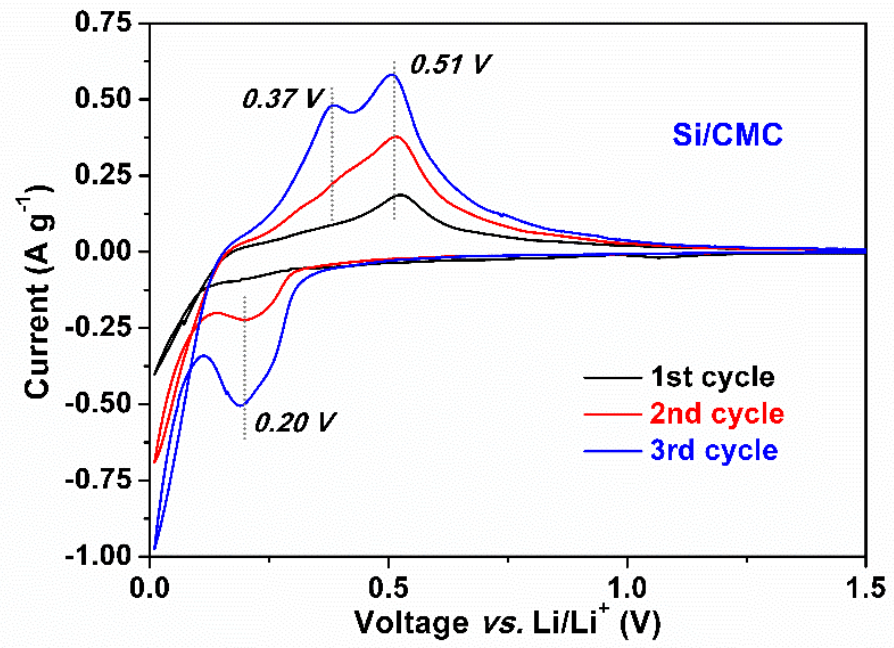

Figure S8. CV curves of $\mathrm{Si} / \mathrm{CMC}$ anodes at a scanning rate of $0.1 \mathrm{mV} \mathrm{s}^{-1}$ of the first 3 cycles. 


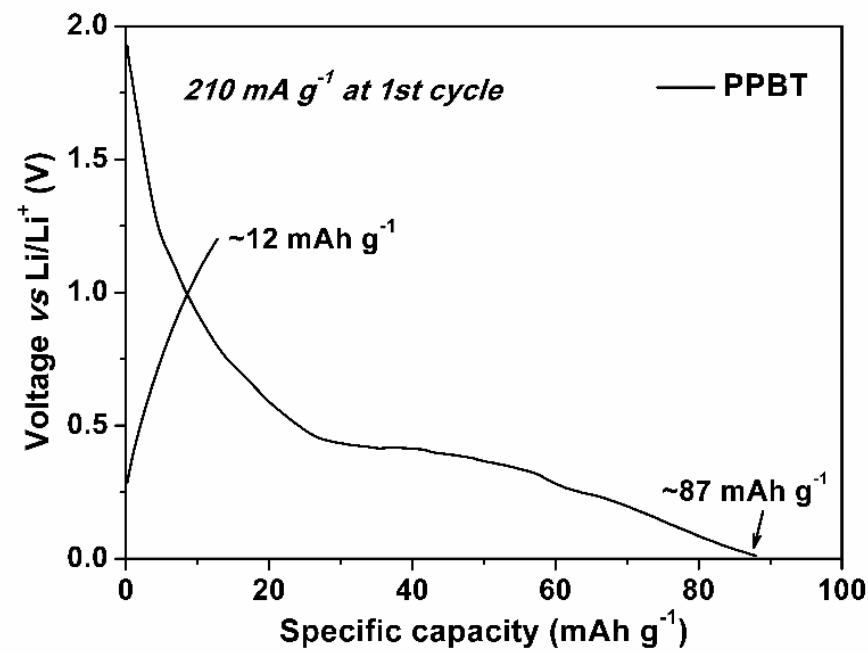

Figure S9. The discharge-charge profiles of PPBT at a current density of $\sim 210 \mathrm{~mA} \mathrm{~g}^{-1}$. 

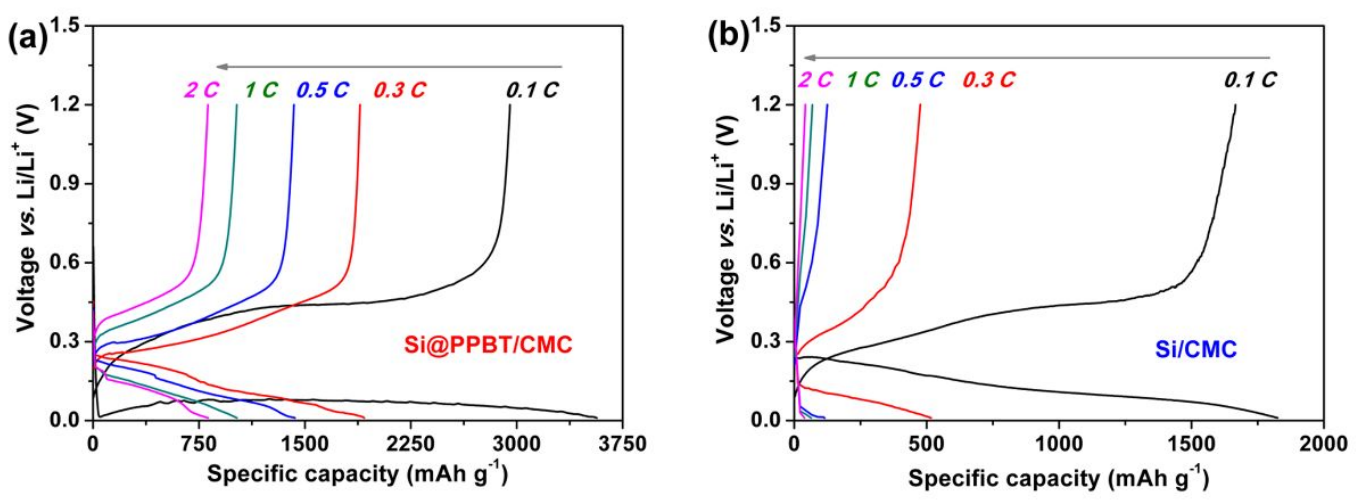

Figure S10. The discharge-charge profiles of (a) Si@PPBT/CMC and (b) Si/CMC anodes at different rates. 


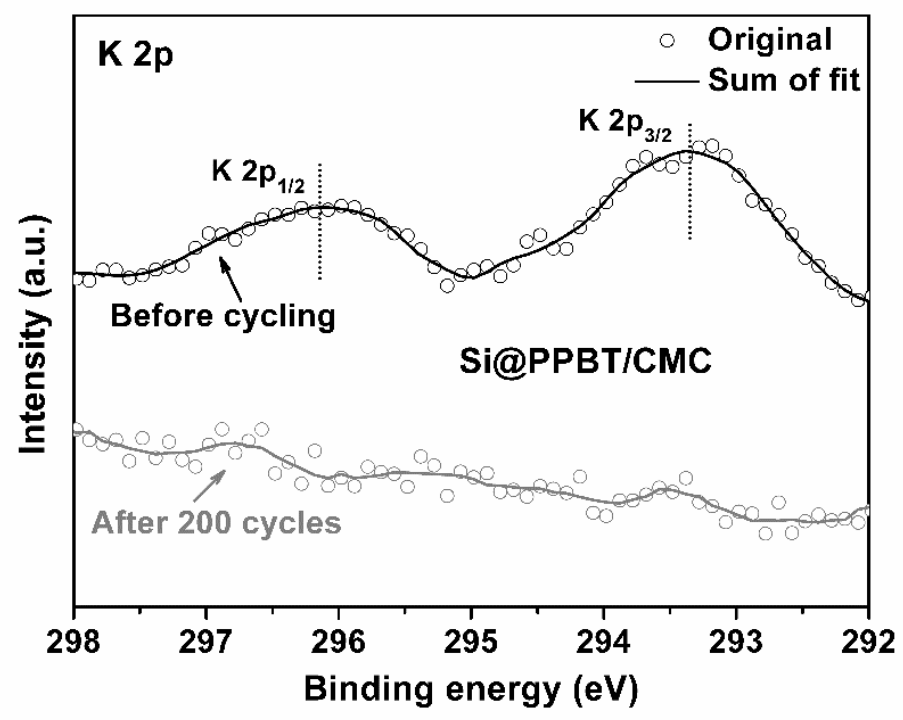

Figure S11. High-resolution XPS spectra (K 2p) of Si@PPBT/CMC anode after 200 cycles. 

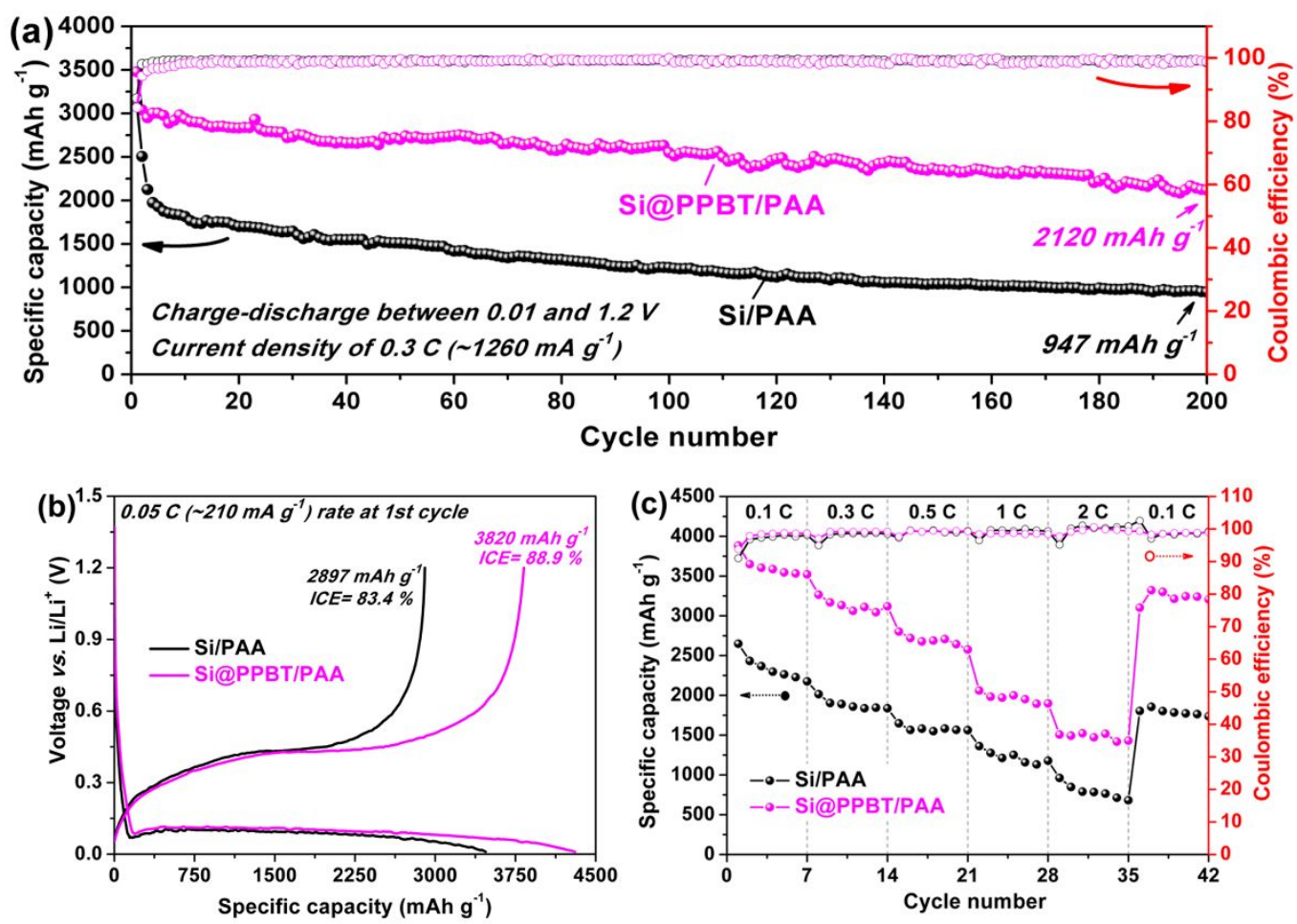

Figure S12. Electrochemical characterization of Si@PPBT and Si nanoparticle anodes fabricated using PAA binder. (a) The cycling performance of the two anodes at a charge/discharge current density of $0.3 \mathrm{C}$ (open circles: Coulombic efficiency). (b) The discharge-charge profiles of Si@PPBT/PAA and Si/PAA anodes at first cycle at a current density of 0.05 C. (c) Rate capability comparison measured at different discharge current densities in the range of 0.1-2 $\mathrm{C}$ (open circles: Coulombic efficiency). 
Table S1. The impedance parameters of Si@PPBT/CMC and Si/CMC before and after cycling for 200 cycles.

\begin{tabular}{lcccc}
\hline Sample & \multicolumn{2}{c}{ Si@PPBT/CMC } & \multicolumn{2}{c}{ Si/CMC } \\
& $\mathbf{R}_{\mathbf{s}}(\boldsymbol{\Omega})$ & $\mathbf{R}_{\mathrm{ct}}(\boldsymbol{\Omega})$ & $\mathbf{R}_{\mathbf{s}}(\boldsymbol{\Omega})$ & $\mathbf{R}_{\mathrm{ct}}(\boldsymbol{\Omega})$ \\
\hline $\mathbf{0}$ cycle & 7.6 & 113.1 & 9.2 & 163.9 \\
$\mathbf{2 0 0}$ cycle & 10.8 & 179.8 & 18.9 & 311.4 \\
\hline
\end{tabular}


Table S2. Comparison of electrochemical performances of Si based anodes.

\begin{tabular}{|c|c|c|c|c|c|}
\hline $\begin{array}{c}\text { Active } \\
\text { materials }\end{array}$ & Binder $^{a}$ & $\begin{array}{l}\text { Current density } \\
\qquad\left(\mathrm{mA} \mathrm{g} \mathrm{g}^{-1}\right)\end{array}$ & $\begin{array}{c}\text { Cycle number } \\
\text { (n) }\end{array}$ & 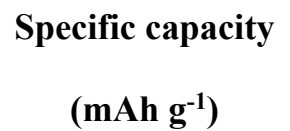 & Ref. \\
\hline \multirow[t]{2}{*}{ Si@PPBT } & $\mathrm{CMC}$ & 1260 & $200 / 100$ & $1793 / 2008$ & This work \\
\hline & PAA & 1260 & $200 / 100$ & $2120 / 2550$ & \\
\hline $\mathrm{Si}$ & chitosan & 200 & 100 & 766 & 1 \\
\hline $\mathrm{Si}$ & Alginate & 4200 & 100 & 1700 & 2 \\
\hline $\mathrm{Si}$ & C-chitosan & 500 & 100 & 1969 & 3 \\
\hline $\mathrm{Si}$ & PAA-PVA & 4000 & 50 & 1800 & 4 \\
\hline $\mathrm{Si}$ & PAA-PVA & 200 & 80 & 1250 & 5 \\
\hline $\mathrm{Si}$ & PEDOT:PSS & 1000 & 100 & 2071 & 6 \\
\hline $\mathrm{Si} / \mathrm{C}$ & Alginate & 420 & 120 & 1822 & 7 \\
\hline $\mathrm{Si}$ & B-cyclodextrin & 4200 & 200 & 1600 & 8 \\
\hline $\mathrm{Si}$ & Pyrrole & 2000 & 400 & 1480.3 & 9 \\
\hline $\mathrm{Si}$ & KGM & 2000 & 1000 & 841 & 10 \\
\hline
\end{tabular}

${ }^{a}$ C-chitosan: cross-linked chitosan; KGM: konjac glucomannan.

\section{References}

1. Yue, L.; Zhang, L.; Zhong, H., Carboxymethyl Chitosan: A New Water Soluble Binder for Si Anode of Li-Ion Batteries. J. Power Sources 2014, 247, 327-331.

2. Kovalenko, I.; Zdyrko, B.; Magasinski, A.; Hertzberg, B.; Milicev, Z.; Burtovyy, R.; Luzinov, I.; Yushin, G., A Major Constituent of Brown Algae for Use in High-Capacity Li-Ion Batteries. Science 2011, 334 (6052), 75-79.

3. Chen, C.; Lee, S. H.; Cho, M.; Kim, J.; Lee, Y., Cross-Linked Chitosan as an Efficient Binder for Si Anode of Li-Ion Batteries. ACS Appl. Mater. Interfaces 2016, 8 (4), 2658-2665.

4. Song, J.; Zhou, M.; Yi, R.; Xu, T.; Gordin, M. L.; Tang, D.; Yu, Z.; Regula, M.; Wang, D., Interpenetrated Gel Polymer Binder for High-Performance Silicon Anodes in Lithium-Ion Batteries. Adv. Func. Mater. 2014, 24 (37), 5904-5910. 
5. Jeena, M.; Lee, J.-I.; Kim, S. H.; Kim, C.; Kim, J.-Y.; Park, S.; Ryu, J.-H., Multifunctional Molecular Design as an Efficient Polymeric Binder for Silicon Anodes in Lithium-Ion Batteries. ACS Appl. Mater. Interfaces 2014, 6 (20), 18001-18007.

6. Higgins, T. M.; Park, S.-H.; King, P. J.; Zhang, C.; McEvoy, N.; Berner, N. C.; Daly, D.; Shmeliov, A.; Khan, U.; Duesberg, G., A Commercial Conducting Polymer as both Binder and Conductive Additive for Silicon Nanoparticle-Based Lithium-Ion Battery Negative Electrodes. ACS Nano 2016, 10, (3), 3702-3713.

7. Liu, J.; Zhang, Q.; Wu, Z.-Y.; Wu, J.-H.; Li, J.-T.; Huang, L.; Sun, S.-G., A High-Performance Alginate Hydrogel Binder for the Si/C Anode of a Li-Ion Battery. Chem. Commun. 2014, 50 (48), 6386-6389.

8. Jeong, Y. K.; Kwon, T.-w.; Lee, I.; Kim, T.-S.; Coskun, A.; Choi, J. W., Hyperbranched $\beta$-Cyclodextrin Polymer as an Effective Multidimensional Binder for Silicon Anodes in Lithium Rechargeable Batteries. Nano lett. 2014, 14 (2), 864-870.

9. Liu, J.; Wu, J.; Wang, Z.; Qi, M.; Wang, Y., N-Doped Gel-structure Constructs Long Cycling Si Anodes at High Current Densities for High Performance Lithium-Ion Batteries. J. Mater. Chem. A 2019, 7, 11347-11354.

10. Guo, S.; Li, H.; Li, Y.; Han, Y.; Chen, K.; Xu, G.; Zhu, Y.; Hu, X., $\mathrm{SiO}_{2}$-Enhanced Structural Stability and Strong Adhesion with a New Binder of Konjac Glucomannan Enables Stable Cycling of Silicon Anodes for Lithium-Ion Batteries. Adv. Energy Mater. 2018, 8, (24), 1800434. 